\title{
Quality of life in chronic trigeminal neuralgia patients*
}

\author{
Qualidade de vida em pacientes com neuralgia trigeminal crônica \\ Priscila Brenner Hilgenberg-Sydney ${ }^{1}$, Bianca Marques Calles ${ }^{2}$, Paulo César Rodrigues Conti ${ }^{2}$ \\ ${ }^{*}$ Received the University of São Paulo, Bauru School of Dentistry, Bauru, SP, Brazil.
}

DOI 10.5935/1806-0013.20150039

\section{ABSTRACT}

BACKGROUND AND OBJECTIVES: Trigeminal neuralgia is a debilitating painful condition found in some patients. It is classified as neuropathic episodic pain, reported as "electric shock", "burning" and/or "tingling". This study aimed at evaluating the impact of trigeminal neuralgia on quality of life and its association with pain duration.

METHODS: Participated in the study 20 patients above 40 years of age, who were divided in two groups. Group I was was comprised of 10 trigeminal neuralgia patients and group II of healthy painless patients. All patients have filled a visual analog scale about pain severity and the Oral Health Impact Profile questionnaire about quality of life. Group I patients were also asked about time of pain onset. Data were recorded and submitted to statistical analysis (Spearman correlation and Mann-Whitney tests).

RESULTS: Trigeminal neuralgia significantly and negatively impacts quality of life $(\mathrm{p} \leq 0.01)$. However, neither pain intensity nor pain duration seem to be associated with this result.

CONCLUSION: Trigeminal neuralgia negatively impacts quality of life regardless of pain intensity.

Keywords: Chronic pain, Facial pain, Quality of life, Trigeminal neuralgia.

\section{RESUMO}

JUSTIFICATIVA E OBJETIVOS: A neuralgia trigeminal é uma condição dolorosa debilitante encontrada em alguns pacientes. É classificada como uma dor neuropática episódica, reportada como "choque elétrico", "queimação" e/ou "formigamento". O objetivo deste estudo foi avaliar o impacto da neuralgia trigeminal na qualidade de vida e sua associaçáo com o tempo de dor.

1. Universidade Tuiuti do Parana, Curitiba, PR, Brasil.

2. Universidade de São Paulo, Faculdade de Odontologia de Bauru, Bauru, SP, Brasil.

Submitted in April 06, 2015.

Accepted for publication in July 06, 2015.

Conflict of interests: none - Sponsoring sources: CAPES and FAPESP

\section{Correspondence to:}

Priscila Brenner Hilgenberg-Sydney

Rua Octávio Pinheiro Brisola, 9-75 - Vila Universitária

17012-901 Bauru, SP, Brasil.

E-mail: priscilabhs@me.com

( ) Sociedade Brasileira para o Estudo da Dor
MÉTODOS: Foram avaliados 20 pacientes, acima de 40 anos, divididos em 2 grupos. O grupo I foi formado por 10 pacientes com neuralgia trigeminal e o grupo II por 10 pacientes saudáveis, sem dor. Todos os pacientes preencheram uma escala analógica visual sobre a gravidade da dor e o questionário Oral Health Impact Profile sobre qualidade de vida. Os pacientes do grupo I também foram questionados sobre o tempo de início da dor. Os dados foram registrados e submetidos a análise estatística (testes de correlação de Spearman e de Mann-Whitney).

RESULTADOS: A presença da neuralgia trigeminal tem impacto significativo e negativo na qualidade de vida $(\mathrm{p} \leq 0,01)$. No entanto, nem a intensidade da dor, nem o tempo de dor parecem estar associados a esse resultado.

CONCLUSÂO: A neuralgia trigeminal exerce um impacto negativo na qualidade de vida, não importando a intensidade da dor.

Descritores: Dor Crônica, Dor Facial, Neuralgia trigeminal, Qualidade de vida.

\section{INTRODUCTION}

According to the International Headache Society (IHS) ${ }^{1}$, trigeminal neuralgia $(\mathrm{TN})$ is an episodic neuropahtic pain, reported as electric shock, disabling and intense. Pain is felt in the area innervated by the trigeminal nerve, most commonly the second and/ or the third divisions ${ }^{2}$. Diagnosis is made primarily by clinical history and anamnesis. Pain is fast, lasts just a few seconds and is unilateral, in a branch of the distribution of the affected nerve being triggered by a stimulus generally mild and not harmful (eg. shaving, combing hair, speaking) of a trigger zone. There is a latency period between each episode and painful attacks are stereotyped in each patient.

The understanding and management of patients with chronic orofacial pain is probably the biggest challenge faced by professionals ${ }^{2,3}$. Individuals with chronic pain have a multifactorial problem with physical and psychosocial symptoms ${ }^{4,5}$. Recognizing the psychological components of pain is critical to conduct an effective treatment ${ }^{6}$. The pathophysiology of TN has recieved more attention in the literature over the past years. However, it is been suggested that facial pain needs to be viewed from a global perspective, including not only biological features but also their social and psychologic influences. That is particullary interesting because one can better understand the health outcomes and disease impact on quality of life (QL). According to the biobehavioral model of disease, emotions can facilitate or inhibit orofacial pain. Physical discomfort, behavioral and functional limitations and psychosocial disability, may influence on how one can res- 
pond to a treatment modality and also indicate if it is being successful ${ }^{7,8}$. Chronic pain has multiple etiologies thus, hearing TN patients' emotional, social, functional and behavioral complaints improves doctor's diagnosis of this poorly understood condition. Despite TN being a very debilitating disease, there are not many papers in the literature that specifically assess the QL of patients with trigeminal neuralgia ${ }^{2}$.

The aim of this cross-sectional preliminary study was to evaluate the impact of TN and pain intensity on QL.

\section{METHODS}

Sample was comprised of twenty female volunteers up to 40 years old, selected from individuals seeking treatment for orofacial pain at Bauru School of Dentistry Orofacial Pain Center. Two groups were formed, according to the following criteria. Group I was comprised of 10 patients with classical TN pain, according the IHS criteria ${ }^{1}$, without prior treatment. The IHS criteria for TN are: unilateral disorder characterized by brief electric shock-like pains, abrupt in onset and termination, limited to the distribution of one or more divisions of the TN. Pain is commonly evoked by trivial stimuli including washing, shaving, smoking, talking and/or brushing the teeth and frequently occurs spontaneously. Small areas in the nasolabial fold and/or chin may be particularly susceptible to the precipitation of pain. Pains usually remit for variable periods.

\section{Diagnostic criteria}

1. Paroxysmal attacks of pain lasting from a fraction of a second to 2 minutes, affecting one or more divisions of the TN.

2. Pain has at least one of the following characteristics:

- Intense, sharp, superficial or stabbing;

- Precipitated from trigger areas or by trigger factors;

- Attacks are stereotyped in the individual patient;

- There is no clinically evident neurological deficit;

- Not attributed to another disorder.

All TN patients had unilateral pain, affecting V2 branch of the TN. Four of them had pain on the left side and 6 of them had pain on the right side. All patients were experiencing frequent daily paroxistic pain, with few seconds of duration, for at least 90 days. None of them had already been submitted to any invasive and/or surgical treatment modality prior to the present evaluation. Patients from Group I were selected from those seeking treatment for orofacial pain and by the time of the present study were already taking $300 \mathrm{mg} /$ day of carbamazepine for 7 days. Group II was comprised of 10 healthy and painless female patients. Those patients were recruited by advertisement. Illiterate and/or patients with history or diagnosis of mental or psychosomatic disorders, headaches and/or multiple sclerosis were excluded from the sample.

Mean pain intensity was obtained through a visual analog scale (VAS) ranging from 0 to $100 \mathrm{~mm}$. Time of pain onset was questioned and recorded in months. To evaluate the impact of TN on daily life of patients, the Oral Health Impact Profile (OHIP) modified for orofacial pain patients was used. In this inventory, the final score varies from 0 to 30 and higher scores indicate a hi- gher impact of pain on patient's quality of life. All subjects were interviewed once by the same examiner. After that, they were all referred for treatment.

Statistical analysis was performed using Spearman correlation and Mann-Whitney tests to verify the correlation and association between variables: pain onset, pain intensity and quality of life. The level of significance was set at 5\%.

All subjects signed the informed consent to procedures approved by the Ethics Committee of Bauru School of Dentistry, University of São Paulo, protocol \#139/2009.

\section{RESULTS}

Twenty patients with age between 41 and 75 years were evaluated. Statistical analysis showed that there was a significant difference between groups for age and for quality of life. Table 1 shows mean age and OHIP mean scores for both groups.

Table 1. Mean age (years) and quality of life (OHIP mean scores) by groups

\begin{tabular}{lccc}
\hline & Group I & Group II & p value \\
\hline Age & $62.40 \pm 11.24$ & $47.70 \pm 4.83$ & $0.00^{*}$ \\
Quality of life & $16.90 \pm 6.59$ & $1.10 \pm 2.33$ & $0.00^{*}$ \\
\hline
\end{tabular}

*Statistically significant.

For group I, duration of pain was found to vary from 18 to 360 months. Mean pain intensity varied from 26 to $100 \mathrm{~mm}$ in the VAS, with a mean value of $73.30 \pm 28.79$. Correlation tests were performed between OHIP score and pain intensity $(\mathrm{R}=0.18$, $\mathrm{p}=0.62)$, as well as pain onset and VAS $(\mathrm{R}=-0.56, \mathrm{p}=0.09)$ and OHIP score and time of pain onset $(\mathrm{R}=-0.47, \mathrm{p}=0.17)$. However, none of them was statistically significant.

\section{DISCUSSION}

Differences in mean age between groups were already expected. It is known that TN has a higher prevalence between subjects above 50 years old'. Mean age results found for group I are in accordance with other authors ${ }^{10}$. Healthy patients from group II had a significantly lower mean age than experimental group. This was probably because younger patients, with the same age of group I, who did not have TN, or any other disease here considered as exclusion criteria, are not easliy found in the general population.

According to previous articles ${ }^{8,11}$, patients with orofacial pain seem to have a handicap in quality of life. The same was found in the present study, where TN patients showed a significant handicap in their quality of life when compared to those without pain. There are no studies in the literature similar to the present one, using the OHIP questionnaire modified for patients with orofacial pain. Therefore, there are no numeric values for comparison. However, some studies with a similar general conclusion will be presented and discussed.

Unlike patients with Temporomandibular Disorders ${ }^{12}$, TN patients do not have a greater impact on quality of life the more severe is pain intensity. Moreover the mean score obtained for 
OHIP in TMD patients is lower, about $11.74^{11}$. Perhaps TN is a condition so disabling that only being there, even in mild intensity, is enough to poorly and significantly influence the quality of life of the individual.

The OHIP questionnaire proved to be a good simple tool to assess the impact of the presence of trigeminal neuralgia in patients' lives and also may serve as a marker of efficacy of different treatment modalities for this condition. This can be done using other QL questionnaires, such as the 36-item Short Form Health Survey (SF-36). It is suggested that the recovery of a surgery may be influenced by QL factors. TN patients who underwent microvascular decompression (MVD) took almost a year to recover from social and emotional limitations ${ }^{13}$. A short form of this same questionnaire, SF-36 was used to evaluate the long term effect of Gamma Knife Surgery in TN patients. On a scale from 0 to 10 , patients rated a mean score of $7.8 \pm 3.1$ for their QL after treatment. And $61 \%$ indicated that pain did not interfere with their normal daily activities ${ }^{14}$. Although none of these two studies measured QL score prior to surgical intervention, which prevents outcome comparisons. Another study ${ }^{15}$ evaluated TN patients' QL using part of the EuroQol EQ-5D questionnaire, before and after intervention with radiofrequency thermocoagulation of the Gasserian ganglion. Baseline QL scores varied from 27.8 to 32.0 on a 0 to 100 scale. After radiofrequency treatment all TN patients had a statistically significant improvement of QL. These authors did find a significant correlation between pain intensity and $\mathrm{QL}(\mathrm{R}=0.93)$, unlike the present study $(\mathrm{R}=0.18)$. In addition, all patients here evaluated in group I had TN pain persisting at least for more than 3 to 6 months, which can be considered as chronic pain. It is known that chronic pain is associated with psychological symptoms and persistent central sensitization of the central nervous system ${ }^{2}$. Macianskyte et al. ${ }^{5}$ conducted a study with 30 patients with TN and chronic unspecified facial pain, and 30 patients with atypical facial pain. Subjects were evaluated for duration of pain, levels of anxiety and depression through the use of questionnaires. Results showed that patients with TN had higher levels of pain, anxiety and depression when compared to the group of atypical facial pain. A limitation of the present study was not having evaluated depressive and anxiety symptoms in these patients.

Patients with chronic pain experience dramatic changes in their lifestyle, resulting from persistent pain. The frustrations of unsuccessful treatments are added to the suffering caused by pain. With the course of time, often associated with depression, breakdowns occur within the family and the patient becomes in- capacitated. Therefore, in these cases, interventions should be addressed directly to the patient, with the main objective of improving QL through symptom relief, psychotherapy, functional improvement and limitation of disease progression ${ }^{2-4,6}$.

\section{CONCLUSION}

Even considering the small sample and some limitations the present data indicates that presence of TN has a negative impact on patients' quality of life. However, time and intensity of pain do not seem to influence such association.

\section{ACKNOWLEDGMENTS}

CAPES-Brazil and FAPESP-Brazil for the financial support.

\section{REFERENCES}

1. The International Classification of Headache Disorders: $2^{\text {nd }}$ edition. Headache Classification Subcommittee of the International Headache Society. Cephalalgia. 2004;24(Suppl 1):9-160.

2. Zakrzewska JM, McMillan R. Trigeminal neuralgia: the diagnosis and management of this excruciating and poorly understood facial pain. Postgrad Med J. 2011;87(1028):410-6.

3. Foreman PA, Harold PL, Hay KD. An evaluation of the diagnosis, treatment, and outcome of patients with chronic orofacial pain. N Z Dent J. 1994;90(400):44-8.

4. Fricton JR. Behavioral and psychosocial factors in chronic craniofacial pain. Anesth Prog. 1985;32(1):7-12

5. Macianskyte D, Januzis G, Kubilius R, Adomaitiene V, Sciupokas A. Association between chronic pain and depressive symptoms in patients with trigeminal neuralgia. Medicina (Kaunas). 2011;47(7):386-92.

6. Moran PI, Hunter JJ, Doyle C, Waisman Z. Psychiatric problems in chronic facial pain. Alpha Omegan. 1998;91(2):19-24.

7. Dworkin SF. Perspectives on the interaction of biological, psychological and socia factors in TMD. J Am Dent Assoc. 1994;125(7):856-63.

8. Murray H, Locker D, Mock D, Tenenbaum HC. Pain and the quality of life in patients referred to a craniofacial pain unit. J Orofac Pain. 1996;10(4):316-23.

9. Da Silva AF, Dos Santos MF. The role of sensory fiber demography in trigeminal and postherpetic neuralgias. J Dent Res. 2012;91(1):17-24.

10. Siviero M, Teixeira MJ, de Siqueira JT, Siqueira SR. Somesthetic, gustatory, olfactory function and salivary flow in patients with neuropathic trigeminal pain. Oral Dis. 2010;16(5):482-7.

11. Calderon Pdos S, Hilgenberg PB, Rossetti LM, Laurenti JV, Conti PC. Influence of tinnitus on pain severity and quality of life in patients with temporomandibular disorders. J Appl Oral Sci. 2012;20(2):170-3.

12. Barros Vde M, Seraidarian PI, Cortes MI, de Paula LV. The impact of orofacial pain on the quality of life of patients with temporomandibular disorder. J Orofac Pain. 2009;23(1):28-37.

13. Shibahashi K, Morita A, Kimura T. Surgical results of microvascular decompression procedures and patient's postoperative quality of life: review of 139 cases. Neurol Med Chir. 2013;53(6):360-4.

14. Young B, Shivazad A, Kryscio RJ, St.Clair W, Bush HM. Long-term outcome of high-dose Gamma Knife surgery in treatment of trigeminal neuralgia. J Neurosurg. 2013;119(5):1166-75.

15. Li X, Ni J, Yang L, Wu B, He M, Zhang X, et al. A prospective study of Gasserian ganglion pulsed radiofrequency combined with continuous radiofrequency for the treatment of trigeminal neuralgia. J Clin Neurosci. 2012;19(6):824-8. 